Journal of Research in Interprofessional

Practice and

Education

Vol. 6.1

June 2016
Journal of Research in Interprofessional Practice and Education (JRIPE)

Vol. 6.1

(C) 2016

Corresponding author: Alison Bealle Rudd. Email: arudd@southalabama.edu

\section{Examining Undergraduate Nursing Student Professional Stereotypes in an Interprofessional Education Simulation Experience}

\author{
Alison Bealle Rudd, EdD, RN; Julie M. Estis, Ph.D., CCC-SLP; \\ Bill Pruitt, MBA, RRT; Theresa Wright, RN, DNP, CCRC
}

\begin{abstract}
Background: Interprofessional education (IPE) provides a platform for early professional socialization, potentially affecting the accuracy of stereotypes among health professions students. The purpose of this study was to implement an interprofessional simulation with nursing, respiratory therapy (RT), and speech language pathology (SLP) students, and using the Student Stereotype Rating Questionnaire, evaluate how an IPE simulation approach may alter stereotypes that learners carry with them related to themselves and professions other than their own.

Methods and Findings: Participants rated the extent to which they believe attributes, based on nine professional characteristics, apply to either their own profession (autostereotypes), other professions (heterostereotypes), or their own profession as seen by others (perceived autostereotypes) with the Student Stereotype Rating Questionnaire (SSRQ). A quasi-experimental pretest-posttest design was used, and descriptive and analytical statistics conducted within and across groups. Participant impressions of the IPE experience are presented. Main limitations included smaller sample size of RT and SLP participants.

Conclusions: Results showed a significant difference from pre- to post-IPE simulation in nursing heterostereoptype, autostereotype, and perceived autostereotype scores. No significant difference was seen in hetereostereotypes of RT and SLP students. Overall, student impressions were positive. Recommendations include study replication for larger sample size.
\end{abstract}

Keywords: Interprofessional education; Simulation; Health professions education; Stereotypes; Passy-Muir Valve

\section{Introduction}

There is a needed and growing transformation in healthcare for professionals to collaborate with one another for improved patient care [1]. Even as all the body's parts work together, so professionals in their fields can work together and accomplish more improved patient outcomes that no single health professional can. For most health professionals, collaboration must be learned, as it does not come naturally for individuals who choose these professions.

In recent years, health professions (HP) educators have been answering the call of the Institute of Medicine, accrediting bodies, and other advisory councils for stu- 
2

Nursing Student Professional Stereotypes

Rudd, Estis, Pruitt, \& Wright
Journal of Research in Interprofessional

Practice and

Education

Vol. 6.1

June 2016 dents to be prepared for purposeful collaboration, with the shared objective of constructing a more patient-centered and community-oriented healthcare system. Interprofessional education (IPE) in HP training has been shown to enhance collaborative care in practice, thereby improving patient outcomes. IPE also provides a platform for early professional socialization, potentially affecting the accuracy of stereotypes among pre-professional students [1]. Simulation provides a controlled setting that facilitates evaluation of student preparedness for functioning as healthcare team members. Just as in practice, students in the simulation lab struggle with roles, capabilities, skills, and other proficiencies needed to work as a team [2]. Expectantly, learning together through simulated clinical scenarios will lead to a future of improved working together.

Needed change brings challenges. In HP education, barriers to IPE may present themselves in many ways. These include, but are not limited to, institutional challenges, faculty development issues, assessment concerns, and existing perceptions [1]. "Existing perceptions" refers to dissimilarities among the professional groups, and how these disparities may pose a challenge to the health delivery arena. While it is effective to have a variety of experts consulting in the care of a patient, for those experts to remain fragmented due to dissimilarity and misunderstandings, becomes ineffective and unsafe [3].

Amy Edmonson and Kate Roloff refer to these HP differences as "variety diversity" [4, p. 183]. Because of the abundance of professional differences in an ever-evolving healthcare system, stereotyping of professional roles, both positive and negative, has a very real existence among health professionals [5]. For HP students, attitudes and ideas are formed through socialization and how other professions are represented inside their training. These stereotypes may be accurate or inaccurate [6]. Stereotyping is a natural human process that can be either positive or negative. What is fundamental is that HP students find exactness. The tool used for this study was the Student Stereotype Rating Questionnaire (SSRQ), originally drawn from the work of Diana Barnes, John Carpenter, and Claire Dickinson [7]. Examining nurses, psychologist, therapists, social workers, resource workers, and psychiatrists within an IPE approach to community mental health, Barnes et al. found that interprofessional stereotypes and perceived status differences do exist. The work of Barnes and colleagues was based on similar characteristics evaluating autostereotypes, heterostereotypes, and perceived autostereotypes [7]. The terms autostereoype, heterostereotype, and perceived autostereostype will be used frequently throughout this article [8] and are defined in Table 1.

\section{Table 1. Definitions of stereotypes}

\begin{tabular}{|l|l|}
\hline Stereotype & Definition \\
\hline Autostereotype & belief or attitude about one's own profession \\
\hline Heterostereotype & belief, attitude, or perception about a profession different from one's own \\
\hline Perceived Autostereotype & belief or attitude about one's own profession as seen by others \\
\hline
\end{tabular}


3

Nursing Student

Professional

Stereotypes

Rudd, Estis, Pruitt, \& Wright

Journal of Research in Interprofessional Practice and Education

Vol. 6.1

June 2016
Stereotypical beliefs and attitudes may already be rooted when students become practicing health professionals [6]. Therein lays the challenge for HP educators: position groundwork in training that will enhance the accuracy of professional stereotypes and nurture attitudes that value professional diversity. Professional socialization begins in HP education [9]. Early participation by students in IPE can help to lay a foundation for collaborative practice that will continue into their respective professions and ultimately create a safer healthcare system for patients and families [10].

\section{Problem statement}

Stereotypes among the disciplines have the potential to erode mutual respect and inhibit the ability to work as a collaborative team. Collaborative care is defined as practicing health professionals working in teams, and has been shown to be effective in providing safer, higher-quality patient care [11]. While diverse teams can be effective teams, the ability to understand and appreciate one another's differences underpins the idea of collaborative care [4]. The major issues related to this study are: 1) inaccurate stereotypes exist among practicing health professionals, and 2) these existing stereotypes set a precedent for potentially unsafe and non-collaborative patient care.

\section{Conceptual framework}

The framework used in this study is the Medical University of South Carolina (MUSC) conceptual framework for advancing IPE [12]. MUSC's illustration of a "learning spiral" is conceptualized around two domains: building teamwork competencies and transforming ways of knowing. The framework draws from three different adult learning theories and illustrates a learner's development in three phases of learning - acquisition, application, and demonstration. The first phase, prepare oneself as a team member, is where this study is focused. The MUSC framework illustrates that learners must prepare themselves to be part of the healthcare team and become cognizant of the fact that they carry with them stereotypes, beliefs, and attitudes of other professionals that may hinder or enhance collaborative education and practice [12,13]. A greater understanding of not just one's own role, but the roles of others on the healthcare team will aid learners in progressing through the ways of knowing, which will ultimately lead to a collaborative culture for healthcare delivery.

\section{Review of the literature}

In order to examine the literature surrounding the significance of IPE in HP education, and how it relates to stereotypes that exist among health professionals, three major areas of the literature were reviewed: 1) the meaning of IPE and its role in HP education, 2) utilization of simulation for IPE in HP education, and 3) stereotyping within IPE, including instruments and tools. Reports, such as Learning Together to Work Together for Health and Health Professions Education: A Bridge to Quality, are cited often in the literature and challenge educators to use IPE in HP programs in order to prepare students for collaborative practice [9,11,14-17]. Justification for IPE has come from the acknowledgement that healthcare teams that practice collabora- 
4

Nursing Student Professional Stereotypes

Rudd, Estis, Pruitt, \& Wright

Journal of Research in Interprofessional Practice and Education

Vol. 6.1

June 2016 tively create a culture of quality and safety [18]. This systems-based approach to care has surpassed its days of popularity, and has progressed into categorical necessity.

There is a common theme in the literature regarding the need for more comprehensive assessment approaches and tools; largely that empirical evidence is needed to support the use of IPE over uniprofessional education $[9,19,20]$. Completed research has focused mostly on learner readiness, attitudes, knowledge attainment, and skill development [18]. As more HP training programs move toward competency-based curriculums, the ability to evaluate the effectiveness of pedagogical tools and interventions will become fundamental [21]. The Interprofessional Education Collaborative (IPEC) contends that the evaluation of interprofessional competencies signifies the "next step" in the expansion of IPE, and admits that evaluative development is still in the early stages [1].

Overall, simulation has been found to be an effective platform for IPE. It provides students with a realistic context for training, and, therefore, valuable, relevant learning experiences. Several studies survey student outcomes and impressions related to simulation-based IPE, and discern common results, including improved confidence, knowledge, leadership, teamwork, and communication skills [19].

The concept of stereotyping related to interprofessional interactions first gained importance in the mid-1990s by Carpenter in an evaluation of an interprofessional program for medical and nursing students [8]. Since then, the body of knowledge has expanded to include studies related to a variety of health education students and the concept of stereotyping. Studies by Christine Ateah, Wanda Snow, Pamela Wener, Laura MacDonald, Colleen Metge, Penny Davis, Moni Fricke, Sora Ludwig, and Judy Anderson and Sara Robben, Marieke Perry, Leontien van Nieuwenhuijzen, Theo van Achterberg, Marcel Olde Rikkert, Henk Schers, Maud Heinen, and René Melis examined if characteristics, or perceptions, collected at the time of initial assessment were changed by an IPE experience [22,23]. Sarah Hean, Jill Clark, Kim Adams, and Debra Humphris and Linda Bell and Lucille Allain examined stereotypes at baseline, and as a means to begin a discourse about stereotypical assumptions of HP students and how assumptions can impact student learning and IPE [6,24,25]. A consistent premise in each study was that learners have attitudes and perceptions about other professional groups, and that IPE has the potential to further develop students' knowledge of professional roles, thereby exacting stereotypes. Several studies also examined stereotypes that learners carry with them related to their own professional role $[6,7,24,25]$.

The IPEC discusses stereotyping in its roles and responsibilities competency, stating that because diversity in the workforce exists, it is necessary to examine pre-existing notions, or stereotypes, and how they may affect IPE [1]. One study suggests stereotyping may become a barrier to IPE, but at the same time it proposes that stereotypes will serve to enhance patient-centred collaborative care as long as the discourse ensues [22]. Overall, research suggests that more inquiries are needed to understand professional role development, including stereotypes, within IPE. The knowledge that each professional role brings with it certain strengths and weaknesses, and how those roles can complement one another, will help to develop an atmosphere of collaborative and patient-centred healthcare [26]. 
JRIPE

5

Nursing Student

Professional

Stereotypes

Rudd, Estis, Pruitt, \& Wright

Limited rubrics exist for evaluating IPE overall. In a comprehensive review of IPE and interprofessional collaboration measurements, it was discovered that most IPE assessments lack adequate theoretical underpinnings and psychometric development [27]. This review was narrowed to finding tools that measure stereotypes, role perception, or participant attitudes toward others, which made limitations even finer. The instruments found are featured in Table 2 and include the SSRQ, the Attitudes to Health Professionals Questionnaire (AHPQ), and the Role Perception Questionnaire (RPQ) $[6,24,28,29]$. The SSRQ was selected for this study.

\section{Table 2. Instruments that measure stereotypes /attitudes of HP students}

\begin{tabular}{|c|c|c|c|c|}
\hline Instrument & Reliability & Validity & Sample & Design \\
\hline $\begin{array}{l}\text { Student Stereotype } \\
\text { Rating } \\
\text { Questionnaire } \\
\text { (SSRQ) } \\
\text { Hean, et al., }[5,6]\end{array}$ & $\begin{array}{l}\text { Test-retest } \\
\text { using } \\
\text { Pearson's R }\end{array}$ & $\begin{array}{l}\text { Content validity } \\
\text { established by } \\
\text { panel of academics, } \\
\text { professionals, and } \\
\text { students }\end{array}$ & $\begin{array}{l}\text { 1,426 first-year students } \\
\text { (SW, radiography, podiatry, } \\
\text { physiotherapy, pharmacy, } \\
\text { OT, nursing, midwifery, } \\
\text { medicine, audiology) }\end{array}$ & $\begin{array}{l}\text { 5-point scale, } \\
9 \text { items }\end{array}$ \\
\hline $\begin{array}{l}\text { Attitudes to Health } \\
\text { Professionals } \\
\text { Questionnaire } \\
\text { (AHPQ) } \\
\text { Lindqvist et al., } \\
\text { [28] }\end{array}$ & $\begin{array}{l}\text { Internal } \\
\text { consistency } \\
(r=0.87)\end{array}$ & $\begin{array}{l}\text { Construct exercise } \\
\text { with various } \\
\text { professionals }\end{array}$ & $\begin{array}{l}\text { (Stage 1) } \\
190 \text { first-year students, } \\
\text { (Stage 2) } \\
160 \text { first-year students } \\
\text { (nursing, medicine, 0T, } \\
\text { pharmacy, midwifery, PT) }\end{array}$ & $\begin{array}{l}20 \text { items, visual } \\
\text { analogue scale, } \\
\text { one construct } \\
\text { with anchors at } \\
\text { each end }\end{array}$ \\
\hline $\begin{array}{l}\text { Role Perception } \\
\text { Questionnaire } \\
\text { (RPQ) } \\
\text { MacKay, } 2004\end{array}$ & $\begin{array}{l}\text { Test-retest } \\
(r=0.7)\end{array}$ & $\begin{array}{l}\text { Content validity } \\
\text { verified through } \\
\text { consultation } \\
\text { with sample group }\end{array}$ & $\begin{array}{l}16 \text { third-year students } \\
\text { (midwifery, nursing, OT, PT, } \\
\text { podiatry, prosthetics and } \\
\text { orthotics, radiography, SW) }\end{array}$ & $\begin{array}{l}10 \text {-point scale, } \\
20 \text { items }\end{array}$ \\
\hline
\end{tabular}

\section{Research questions and hypothesis}

Three research questions guided this study. The study answered the following questions: Is there a difference in:

1. Autostereotypes of nursing students, as measured by the SSRQ, after an IPE approach using simulation?

2. Heterostereotypes of student professional groups nursing, respiratory therapy (RT), and speech language pathology (SLP), as measured by the SSRQ, after an IPE approach using simulation?

3. Perceived autostereotypes of nursing students, as measured by the SSRQ, after an IPE approach using simulation?

Journal of Research in Interprofessional Practice and Education

Vol. 6.1

June 2016
The null hypotheses were:

1. There is no difference in autostereotypes of nursing students after an IPE approach using simulation. 
6

Nursing Student Professional Stereotypes

Rudd, Estis, Pruitt, \& Wright

Journal of Research in Interprofessional Practice and Education

Vol. 6.1

June 2016
2. There is no difference in heterostereotypes of student professional groups nursing, RT, and SLP, after an IPE approach using simulation.

3. There is no difference in perceived autostereotypes of nursing students after an IPE approach using simulation.

Aim

The purpose of this study was to implement an interprofessional simulation with students from nursing, RT, and SLP disciplines, and using the SSRQ, evaluate how an IPE approach may change stereotypes that learners carry with them related to themselves and professions other than their own. Evaluation of stereotypes, using the SSRQ, from pre- to post-IPE simulation was conducted.

\section{Methods}

The research design used was a quasi-experimental pretest-posttest design examining student groups nursing, RT, and SLP. Data collection, by administration of the SSRQ, occurred before and after the IPE simulation experience. Data was analyzed using the Statistical Package for the Social Sciences (SPSS) software and using paired $t$-tests for within group comparisons.

\section{Sample}

The sample consisted of 90 nursing students, 22 SLP students, and 20 RT students. All students were enrolled in the professional portion of their respective training programs. A post hoc power analysis was done using $\mathrm{G}^{\star}$ power found at .90 power with medium effect size 0.5 . Post hoc power analysis found a power of 0.9989 for the nursing group $(n=90), 0.7336$ for the RT group $(n=22)$, and 0.6951 for the SLP group $(n=20)$.

The nursing group $(n=90)$ was comprised of students enrolled in a Bachelor of Science in Nursing (BSN) four-year pre-licensure track, and in their fourth semester of a five-semester program. The SLP group $(n=20)$ was comprised of students enrolled in a Master of Science in SLP program. The SLP program is a two-year course of study, and participants were in their fifth and final semester. Graduate-level SLP students, as opposed to undergraduate speech and hearing sciences students, were chosen due to enrollment in a professional program and course of study. The undergraduate speech and hearing program is foundational, and it is centred on knowledge of basic sciences material. The graduate program includes clinical application and professional expectations, similar to the SLP's nursing and RT counterparts. The RT group $(n=20)$ was comprised of students enrolled in a Bachelor of Science in Cardiorespiratory Care program. The program is a four-year course of study, and participants were in the professional component in their third year. Each cohort of students was selected based on prior knowledge, and the ability of that student group to care for the simulated patient. Each student's ability to have progressed in the curriculum to a certain point served as an indication of prior knowledge, therefore allowing realistic expectations of patient care.

Students were recruited by means of the simulation being part of their coursework. Typically, simulations occur within each course using a uniprofessional model. 
JRIPE

7

Nursing Student

Professional

Stereotypes

Rudd, Estis, Pruitt, \& Wright

Faculty identified the need for an interprofessional model and collaborated. A convenience sampling approach was used. All of the participants invited participated. Participation in the study was voluntary, and informed consent was obtained.

\section{Procedures}

A faculty member from each professional group collected data from his or her respective student groups before the simulation experience. In order to identify factors that may affect student perceptions, or stereotypes, of other student professional groups, a demographic survey was conducted. The SSRQ was administered to the entire cohort (nursing, RT, and SLP students) pre and post IPE simulation. Students were asked to rate autostereotypes (nursing only), heterostereotypes (nursing, RT, and SLP), and perceived autostereotypes (nursing only). See Table 3 for an outline of administration of the SSRQ to each student professional group; pre and post simulation. Before the interprofessional simulation, students completed a brief 45-minute online training module from home. The IPE simulation and debrief took place with all three student groups, nursing, RT, and SLP $(n=132)$ in one day. Immediately following the interprofessional simulation, a post-simulation SSRQ and participant impressions survey were administered. Data analysis took place at the conclusion of these events using paired $t$-test analysis.

\section{Table 3. Student professional groups completing the SSRO pre and post simulation}

\begin{tabular}{|l|l|l|l|}
\hline \multirow{2}{*}{$\begin{array}{l}\text { Pre-simulation } \\
\text { professional groups }\end{array}$} & \multicolumn{4}{|l|}{ Student Stereotype Rating Questionnaire (SSRQ) } \\
\cline { 2 - 4 } & Autostereotypes & Heterostereotypes & Perceived autostereotypes \\
\hline Student nurse & Nursing & SLP \& RT & \multicolumn{1}{|c|}{ Nursing } \\
\hline Student SLP & & Nursing \& RT & \\
\hline Student RT & & Nursing \& SLP & \\
\hline $\begin{array}{l}\text { Post-simulation } \\
\text { professional groups }\end{array}$ & Student Stereotype Rating Questionnaire (SSRQ) & \multicolumn{1}{|l|}{} \\
\cline { 2 - 4 } & Autostereotypes & Heterostereotypes & Perceived autostereotypes \\
\hline Student nurse & Nursing & SLP \& RT & Nursing \\
\hline Student SLP & & Nursing \& RT & \\
\hline Student RT & & Nursing \& SLP & \\
\hline
\end{tabular}

\section{Online module}

Journal of Research in Interprofessional Practice and Education

Vol. 6.1

June 2016

As preparation for the interprofessional simulation, specifically as it relates to the clinical benefits of speaking valves, all three professional groups were asked to view an online module entitled Application of the Passy-Muir Swallowing and Speaking Valves. Passy-Muir is the brand of speaking valves used in the patient scenario, or simulation. The 45-minute online course allowed learners to be equally prepared on aspects of the Passy-Muir valve including design, clinical indications, types of valves, clinical benefits, 
8

Nursing Student

Professional

Stereotypes

Rudd, Estis, Pruitt, \& Wright

Journal of Research in Interprofessional Practice and Education

Vol. 6.1

June 2016 and patient assessment [30]. As assurance that each student viewed the online module prior to the IPE Simulation, participants were prompted to complete a ten-question online quiz and print the course completion certificate. All students were instructed to bring the course completion certificate with them to the IPE simulation.

\section{Simulation}

Before the IPE simulation, students were given patient information including patient name, age, gender, admitting diagnosis, and healthcare provider orders. All three professional student groups were expected to function collaboratively to carry out assessments, treatments, and general care of the patient. Students participated in the simulation in groups of four, consisting of two nursing students, one RT student, and one SLP student per group. A high-fidelity simulator served as the patient, and standardized patients served as family members.

The patient scenario was developed collaboratively by faculty champions from each discipline and was chosen because it incorporates the care of each discipline specifically. In this case, nursing held the role of primary caregiver and advocate. The RT provided assessment, treatment, and care for the patient related to his respiratory disorder. The SLP provided consultation to the patient for speaking valve placement. Because of the faculty members' varied backgrounds, including care of patients similar to the simulated patient, the students experienced a case scenario that is both realistic and relevant to their roles as future healthcare professionals.

\section{Debrief}

After the simulation, students debriefed on the simulation as an interdisciplinary group in a separate classroom, specifically designed for simulation debriefing. Chairs were arranged so that students sat in their simulation team (1 SLP, 1 RT, and 2 nursing students). Faculty from each profession facilitated the discussion about challenges, pitfalls, and successes that occurred within the simulation. The debrief was an opportunity to provide immediate feedback within a supportive climate. After debriefing, students completed the SSRQ and impressions survey in a separate classroom with a proctor present.

\section{Data collection and instruments}

Three tools were used for data collection in the study. In the pre-simulation phase, a demographic survey and SSRQ was given to each student participant. In the postsimulation phase, an impressions survey and SSRQ was administered. Each of these tools is outlined in the following sections.

\section{Demographic survey and participant impressions}

Descriptive analysis of age, gender, clinical experience, and interprofessional collaboration experience was collected by faculty pre simulation and analyzed using SPSS. Students were asked to rate their overall impressions of the IPE simulation experience on a scale of 1 to 5 ( 1 being strongly disagree and 5 being strongly agree). Seven questions were asked using the Likert scale. In addition, two open-ended questions were asked at 


\section{JRIPE}

9

Nursing Student Professional Stereotypes

Rudd, Estis, Pruitt, \& Wright

the end of the survey. They were: 1) Name one thing you learned from this experience, and 2) What would you like to see changed about this activity in the future?

\section{Student Stereotype Rating Questionnaire (SSRQ)}

The instrument used to collect data on student perceptions of both themselves and other HP students is the Student Stereotype Rating Questionnaire (SSRQ). The scale was duplicated with written permission from the author (see Table 4). Perceptions were based on stereotypes the students hold of nine professional characteristics. These nine characteristics are academic ability, professional competence, interpersonal skills (warmth, sympathy, and communication), leadership abilities, ability to work independently, ability to be a team player, ability to make decisions, practical skills, and confidence. Participants were asked to rate the extent to which they believe these attributes apply to either their own profession (autostereotypes), other professions (heterostereotypes), or their own profession as seen by others (perceived autostereotypes), on a five-point scale $(1=$ very low and $5=$ very high) $[6,24]$.

Table 4. Student Stereotype Rating Questionnaire (SSRO)

\begin{tabular}{|l|c|c|c|c|c|}
\hline How would you rate Respiratory Therapists* on: & $\begin{array}{c}\text { Very High } \\
5\end{array}$ & 4 & 3 & 2 & $\begin{array}{c}\text { Very Low } \\
1\end{array}$ \\
\hline Academic ability & & & & & \\
\hline Professional competence & & & & & \\
\hline $\begin{array}{l}\text { Interpersonal skills } \\
\text { (e.g. warmth, sympathy, communication) }\end{array}$ & & & & & \\
\hline Leadership abilities & & & & & \\
\hline The ability to work independently & & & & & \\
\hline The ability to be a team player & & & & & \\
\hline The ability to make decisions & & & & & \\
\hline Practical skills & & & & & \\
\hline Confidence & & & & & \\
\hline
\end{tabular}

*Respiratory therapists are used as an example. Identical questions will be asked about all the other professional groups involved in the study.

\section{Evolution of the SSRQ}

The tool Barnes et al. used for rating professional attributes was based on a sevenpoint scale $(1=$ very low and $7=$ very high $)$. The seven attributes included academic

Journal of Research in Interprofessional Practice and Education

Vol. 6.1

June 2016 rigour, interpersonal skills, communication skills, leadership, practical skills, breadth of life experience, and professional competence [7]. Hean et al. adapted the instrument for use with post-registration students [6,24]. Before its use with study participants, the SSRQ was extensively piloted with a group of 411 health and social care students in England. Content validity was ascertained by a panel of academic profes- 


\section{JRIPE}

10

Nursing Student Professional Stereotypes

Rudd, Estis, Pruitt, \& Wright

sionals, health and social care workers, and pre-registration students. The panel examined each question for clarity, application to the construct it was measuring, and its suitability for first-year pre-registration students. Each item's test-retest reliability was tested using Pearson's R. The items that were shown unreliable over time at a level of five percent significance were rejected [6,24]. The SSRQ has been cited a total of five times in the literature, across four studies [6,22-25].

\section{SSRQ in the literature}

In the Hean et al. study, over 1,400 students across ten professional groups completed the scale. The instrument was extensively piloted, content validity was corroborated, and the tool ultimately developed from the study $[6,24]$. Robben et al. used the nine characteristics established by the Hean et al. study to measure interprofessional attitudes of 80 primary healthcare professionals $[6,23,24]$. Bell and Allain used the SSRQ with a group of 32 students in phase I and 41 students in phase II, in order to help initiate discussions about collaborative practice among students in a child and family specialist social work module [25].

\section{Data analysis}

Data was collected before and after the interprofessional simulation experience. Data analysis was completed by the first author and occurred after the interprofessional simulation. Data was analyzed using the SPSS software and using paired $t$-tests for within group comparisons. Other authors who have used the SSRQ compared mean stereotype ratings made by students of each profession on all nine characteristics, or traits $[6,22,24,25]$. One study also compared a summary mean score of all characteristics as an overall indication of the perception of a profession [22]. Another study used summarized mean scores only in its data analysis [25]. This study used mean stereotype ratings for data analysis. See Table 5 for how each research question was analyzed.

\section{Table 5. Research questions, independent variable, dependent variable, and statistical analysis}

Journal of Research in Interprofessional Practice and Education

Vol. 6.1

June 2016

\begin{tabular}{|l|l|l|l|}
\hline Research question & Independent variable & Dependent variable & Statistical analysis \\
\hline $\begin{array}{l}\text { Is there a difference in autostereotypes of } \\
\text { nursing students, as measured by the SSRQ, } \\
\text { after an IPE approach using simulation? }\end{array}$ & IPE simulation & $\begin{array}{l}\text { Autostereotypes of } \\
\text { Nursing Student } \\
\text { Group }\end{array}$ & Paired $t$-tests \\
\hline $\begin{array}{l}\text { Is there a difference in heterostereotypes } \\
\text { of student professional groups nursing, RT, } \\
\text { and SLP, as measured by the SSRQ, after an } \\
\text { IPE approach using simulation? }\end{array}$ & IPE simulation & $\begin{array}{l}\text { Heterosterotypes of } \\
\text { Nursing, RT, and } \\
\text { SLPStudent Groups }\end{array}$ & Paired $t$-tests \\
\hline $\begin{array}{l}\text { Is there a difference in perceived } \\
\text { autostereotypes of nursing students, as } \\
\text { measured by the SSRQ, after an IPE } \\
\text { approach using simulation? }\end{array}$ & IPE simulation & $\begin{array}{l}\text { Perceived } \\
\text { Autostereotypes of } \\
\text { Nursing Student } \\
\text { Group }\end{array}$ & Paired $t$-tests \\
\hline
\end{tabular}


11

Nursing Student Professional Stereotypes

Rudd, Estis, Pruitt, \& Wright

Journal of Research in Interprofessional Practice and Education

Vol. 6.1

June 2016

\section{Results}

This study examines how an IPE simulation approach affects professional stereotypes among student groups. Results of the study are organized around the three research questions. Using the SSRQ, students rated their stereotypes on nine different characteristics, using a scale of $1-5$ ( 5 being very high and 1 being very low).

\section{Research question 1}

The dependent variable, nursing autostereotypes, demonstrated statistical significance. At an alpha level of .05, there was a significant difference from pre-IPE simulation to post-IPE simulation in nursing autostereotype scores, $t(88)=-2.025,95$ percent CI [-.16697, -.00157$], p=.046, r=.682$, Cohen's $d=-.233$. There was an increase in the mean from $4.6044(S D=.47546)$ to $4.6887(S D=.43058)$.

\section{Research question 2}

The nursing student group was the only group that demonstrated significant difference of heterostereotypes from pre-IPE simulation to post-IPE simulation. The dependent variable, nursing heterostereotypes, demonstrated statistical significance. At an alpha level of .05, there was a significant difference from pre-IPE simulation to post-IPE simulation in nursing heterostereotype scores of RT students, $t(89)=-3.293,95 \%$ CI [-.36717, -.9083], $p=.001, r=.326$, Cohen's $d=-.348$ ) and nursing heterostereotype scores of SLP students, $t(89)=-4.515,95 \%$ CI $[-.50755,-.19734], p<.001, r=.206$, Cohen's $d=-.476$. There was an increase in mean nursing heterostereotype RT scores from $4.2464(S D=.53723)$ to $4.4754(S D=.59581)$ after the IPE simulation and in mean nursing heterostereotype SLP scores from $4.1663(S D=.60733)$ to $4.5188(S D=.56705)$. At an alpha level of .05 , there was not a significant difference from pre-IPE simulation to post-IPE simulation in RT heterostereotype scores of RN students and SLP heterostereotype scores of RN students.

\section{Research question 3}

The dependent variable, nursing perceived autostereotypes, demonstrated statistical significance. At an alpha level of .05, there was a significant difference from pre-IPE simulation to post-IPE simulation in nursing perceived autostereotype scores, $t(80)=-2.682,95 \%$ CI $[-.23591,-.03495], p=.009, r=.585$, Cohen's $d=-.301]$. There was an increase in the mean from $4.4614(S D=.52864)$ to $4.5968(S D=.45914)$ following IPE simulation.

\section{Student impressions}

Participants were given a survey post-IPE simulation to examine impressions of the experience. Participants were asked to rate impressions through 7 questions on a scale of $1-5$ ( 1 being strongly disagree and 5 being strongly agree). Table 6 summarizes results of the impressions survey by student group.

Impression results were examined for the entire group $(n=132)$. The average mean for the entire group of participants was 4.396. Standard Deviation (SD) for $n=132$ was .7405 . Table 7 summarizes results of the impressions survey (questions 1 through 7) overall. 
Table 6. Summary of student group impressions

Nursing Student Professional Stereotypes

Rudd, Estis, Pruitt, \& Wright
Journal of Research in Interprofessional Practice and Education

Vol. 6.1

June 2016

\begin{tabular}{|c|c|c|c|}
\hline Question & $\begin{array}{c}\text { Nursing } \\
\text { mean } \\
\text { std. deviation }\end{array}$ & $\begin{array}{c}\text { RT } \\
\text { mean } \\
\text { std. deviation }\end{array}$ & $\begin{array}{c}\text { SLP } \\
\text { mean } \\
\text { std. deviation }\end{array}$ \\
\hline $\begin{array}{l}\text { I feel better prepared to work with patients with } \\
\text { tracheostomy/speaking valves. }\end{array}$ & $\begin{array}{l}4.3444 \\
.63884\end{array}$ & $\begin{array}{l}4.3636 \\
.72673\end{array}$ & $\begin{array}{l}4.1000 \\
.44721\end{array}$ \\
\hline $\begin{array}{l}\text { I feel better prepared to work with other members of the } \\
\text { healthcare team in providing care for patients with } \\
\text { speaking valves. }\end{array}$ & $\begin{array}{l}4.5444 \\
.67310\end{array}$ & $\begin{array}{l}4.4545 \\
.73855\end{array}$ & $\begin{array}{l}4.2500 \\
.55012\end{array}$ \\
\hline $\begin{array}{l}\text { I have a better understanding of healthcare team member } \\
\text { roles. }\end{array}$ & $\begin{array}{l}4.5444 \\
.65619\end{array}$ & $\begin{array}{l}4.5000 \\
.74001\end{array}$ & $\begin{array}{l}4.2500 \\
.63867\end{array}$ \\
\hline $\begin{array}{l}\text { I feel more comfortable communicating with healthcare } \\
\text { team members. }\end{array}$ & $\begin{array}{l}4.5444 \\
.63884\end{array}$ & $\begin{array}{l}4.5455 \\
.59580\end{array}$ & $\begin{array}{l}4.4000 \\
.59824\end{array}$ \\
\hline The debriefing and group discussions were valuable. & $\begin{array}{l}4.1444 \\
.89394\end{array}$ & $\begin{array}{l}4.3182 \\
.89370\end{array}$ & $\begin{array}{l}4.2500 \\
.85070\end{array}$ \\
\hline $\begin{array}{l}\text { This interprofessional activity was more effective than a } \\
\text { traditional lecture. }\end{array}$ & $\begin{array}{l}4.3667 \\
.81351\end{array}$ & $\begin{array}{l}4.6364 \\
.49237\end{array}$ & $\begin{array}{l}4.5000 \\
1.14708\end{array}$ \\
\hline $\begin{array}{l}\text { I would like to participate in another interprofessional } \\
\text { simulation activity. }\end{array}$ & $\begin{array}{l}4.2778 \\
.86151\end{array}$ & $\begin{array}{l}4.5455 \\
.80043\end{array}$ & $\begin{array}{l}4.4000 \\
.99472\end{array}$ \\
\hline
\end{tabular}

Table 7. Summary of total participant impressions

\begin{tabular}{|c|c|c|c|c|c|c|c|}
\hline & Q1 & Q2 & Q3 & Q4 & Q5 & Q6 & Q7 \\
\hline $\begin{array}{l}\text { Mean } \\
\text { std dev }\end{array}$ & 4.3106 & $\begin{array}{r}4.4848 \\
67093\end{array}$ & 4.4924 & 4.5227 & 4.1894 & 4.4318 & $\begin{array}{r}4.3409 \\
\end{array}$ \\
\hline std.dev & 63164 & 67093. & .67106 & . 62353. & .88354 & .83065 & . 87221 \\
\hline
\end{tabular}

Two open-ended questions were asked on the participant impressions survey. They were: 1) Name one thing you learned from this experience, and 2) What would you like to see changed about this activity in the future? Answers to open-ended questions held the following themes: 1) students liked learning about one another's professional roles, 2) students appreciated learning about the Passy-Muir valve, along with its clinical indications, 3) students learned the importance of communication among caregivers, and 4) students would have liked more preparation material before the simulation and more time with their team before entering the patient's room. Without being directly asked, in all ten debriefing sessions, students verbalized that they would like more IPE simulations. One nursing student commented, "I wish all of our simulations were like this one!" In addition, the question "Would you want to participate in another interprofessional simulation activity if given the opportunity?" was asked of the participants. Table 8 summarizes the results. 


\section{JRIPE}

13

Nursing Student Professional

Stereotypes

Rudd, Estis, Pruitt, \& Wright
Table 8. Participant impressions question:

Would you want to participate in another interprofessional simulation activity if given the opportunity?

\begin{tabular}{|l|l|l|}
\hline Student group & $\begin{array}{l}\text { Yes } \\
\text { frequency (\%) }\end{array}$ & $\begin{array}{l}\text { No } \\
\text { frequency (\%) }\end{array}$ \\
\hline Nursing & $87(97 \%)$ & $3(3 \%)$ \\
\hline Respiratory therapy & $20(91 \%)$ & $2(9 \%)$ \\
\hline SLP & $19(95 \%)$ & $1(5 \%)$ \\
\hline Total & $126(95 \%)$ & $6(5 \%)$ \\
\hline
\end{tabular}

\section{Demographics}

The sample size was 132 participants. Three student groups were represented. Ninety students (68\%) belonged to the nursing student group, 20 (15\%) belonged to the SLP student group, and 22 (17\%) belonged to the RT student group. Information was requested from participants regarding gender, age, clinical experience, setting in which clinical experience occurred, and exposure to interprofessional collaboration.

Demographic information is summarized in Table 9.

Table 9. Demographics

\begin{tabular}{|c|c|c|c|c|c|c|}
\hline & & & & & & \\
\hline & Demographic & & $\begin{array}{c}\text { Nursing } \\
\text { frequency (\%) }\end{array}$ & $\begin{array}{c}\text { Respiratory } \\
\text { frequency (\%) }\end{array}$ & $\begin{array}{c}\text { Speech } \\
\text { frequency (\%) }\end{array}$ & $\begin{array}{c}\text { Total } \\
\text { frequency }(\%)\end{array}$ \\
\hline & & Male & $8(9 \%)$ & 13 (59\%) & $0(0 \%)$ & $21(16 \%)$ \\
\hline & & Female & $82(91 \%)$ & $9(41 \%)$ & $20(100 \%)$ & $111(84 \%)$ \\
\hline & & $20-25$ & $68(75 \%)$ & $9(41 \%)$ & $17(85 \%)$ & 94 (71\%) \\
\hline & & $25-30$ & $9(10 \%)$ & $6(27 \%)$ & $1(5 \%)$ & $16(12 \%)$ \\
\hline & & $30-35$ & $6(7 \%)$ & $7(32 \%)$ & $1(5 \%)$ & $14(11 \%)$ \\
\hline & & $35-40$ & $5(6 \%)$ & $0(0 \%)$ & $0(0 \%)$ & $5(4 \%)$ \\
\hline & & $40-45$ & $2(2 \%)$ & $0(0 \%)$ & $1(5 \%)$ & $3(2 \%)$ \\
\hline & & $>45$ & $0(0 \%)$ & $0(0 \%)$ & $0(0 \%)$ & $0(0 \%)$ \\
\hline & & None & $20(22 \%)$ & $9(41 \%)$ & $1(5 \%)$ & $30(23 \%)$ \\
\hline $\begin{array}{l}\text { Journal of Research in } \\
\text { Interprofessional }\end{array}$ & & $0-5$ years & $70(78 \%)$ & $7(32 \%)$ & $19(95 \%)$ & $96(73 \%)$ \\
\hline Education & & $5-10$ years & $0(0 \%)$ & $5(23 \%)$ & $0(0 \%)$ & $5(3 \%)$ \\
\hline $\begin{array}{l}\text { Vol. } 6.1 \\
\text { June } 2016\end{array}$ & & $10-15$ years & $0(0 \%)$ & $1(4 \%)$ & $0(0 \%)$ & $1(1 \%)$ \\
\hline
\end{tabular}

Journal of Research in Interprofessional Practice and Education 
Table 9. Demographics (continued)

Nursing Student Professional Stereotypes

Rudd, Estis, Pruitt, \& Wright
Journal of Research in Interprofessional Practice and Education

Vol. 6.1

June 2016

\begin{tabular}{|l|l|r|r|r|r|}
\hline \multirow{4}{*}{ Demographic } & \multicolumn{1}{|c|}{$\begin{array}{c}\text { Nursing } \\
\text { frequency (\%) }\end{array}$} & $\begin{array}{c}\text { Respiratory } \\
\text { frequency (\%) }\end{array}$ & $\begin{array}{c}\text { Speech } \\
\text { frequency (\%) }\end{array}$ & $\begin{array}{c}\text { Total } \\
\text { frequency (\%) }\end{array}$ \\
\hline \multirow{4}{*}{ Setting } & Primary care & $6(8 \%)$ & $0(0 \%)$ & $11(58 \%)$ & $17(16 \%)$ \\
\cline { 2 - 6 } & Acute care & $60(86 \%)$ & $7(54 \%)$ & $3(16 \%)$ & $70(69 \%)$ \\
\cline { 2 - 6 } & Long-term care & $2(3 \%)$ & $2(15 \%)$ & $4(21 \%)$ & $8(8 \%)$ \\
\cline { 2 - 6 } & Home health & $0(0 \%)$ & $0(0 \%)$ & $0(0 \%)$ & $0(0 \%)$ \\
\cline { 2 - 6 } & Research & $0(0 \%)$ & $0(0 \%)$ & $0(0 \%)$ & $0(0 \%)$ \\
\cline { 2 - 6 } & 0 ther & $2(3 \%)$ & $4(31 \%)$ & $1(5 \%)$ & $7(7 \%)$ \\
\hline \multirow{4}{*}{$\begin{array}{l}\text { Experience with } \\
\text { interprofessional } \\
\text { collaboration }\end{array}$} & Never & $1(2 \%)$ & $2(15 \%)$ & $2(11 \%)$ & $5(5 \%)$ \\
\cline { 2 - 6 } & Rarely & $30(43 \%)$ & $2(15 \%)$ & $5(26 \%)$ & $37(36 \%)$ \\
\cline { 2 - 6 } & Often & $31(44 \%)$ & $9(70 \%)$ & $8(42 \%)$ & $48(47 \%)$ \\
\cline { 2 - 6 } & Very 0ften & $8(11 \%)$ & $0(0 \%)$ & $4(21 \%)$ & $12(12 \%)$ \\
\hline
\end{tabular}

\section{Discussion}

The research questions examined how an IPE simulation approach can affect autostereotypes, heterostereotypes, and perceived autostereotypes of nursing students, and heterostereotypes of RT and SLP students. IPEC centred one of its IPE competency domains on professional roles and responsibilities [1]. In it, the process of learning how to be a professional is addressed and student obligations are implied, such as learners recognizing that they are categorically dissimilar from other professional groups, but appreciating that in those differences lie value. IPEC encourages realistic and meaningful learning opportunities that will aid learners to recognize, and appreciate their dissimilarities. The importance of this study is primarily manifested by the creation of such an interprofessional environment, as well as utilization of a tool to measure differences in stereotypes among interprofessional groups.

\section{Stereotypes}

Results showing that there was a significant difference from pre-IPE simulation to post-IPE simulation in nursing autostereotype scores reflect that nursing students hold different perceptions of themselves before an IPE simulation than after an IPE simulation with RT and SLP students. Most studies in the literature are related to heterostereotype ratings of HP students; however, some studies examine autostereotypes with varied results. One study examined autostereotypes of health and social care students in a context of exploring distinctions students made of their own professional group (autostereotypes) when compared to the other professional groups (heterostereotype) as part of a baseline analysis [6,7,22-24]. Another study also 
Nursing Student Professional Stereotypes

Rudd, Estis, Pruitt, \& Wright

Journal of Research in Interprofessional Practice and Education

Vol. 6.1

June 2016 examined autostereotypes in order to investigate inter-group differentiation, and found significant difference after IPE [8]. Finally, other researchers assessed autostereotypes of five HP student groups before and after an IPE program, and there was no significant difference [7].

Results related to heterostereotypes of nursing, RT, and SLP indicates that nursing students hold different perceptions of RT and SLP students after an IPE simulation. Similar findings to these are found in the literature. There was a significant difference in heterostereotype summary mean scores between a baseline survey and a survey taken two-and-a-half days after an IPE session; however, there was no significant increase in mean scores on the third survey, which was administered four months later, after interprofessional practice rotations [22]. One study indicates participant heterostereotype scores changed significantly from before the launch of an IPE program to after [23]. Another study reported no significant change in heterostereotype scores from the beginning of a two-year IPE program to after it [7].

Results showed that there was a significant difference from pre-IPE simulation to post-IPE simulation in nursing perceived autostereotype scores. This study reflects that nursing students hold a different perception of their own profession, as it is seen by others, before an IPE simulation and after an IPE simulation with RT and SLP students. One study in the literature examined perceived autostereotype scores of five HP groups-social workers, nurses, occupational therapists, psychiatrists, and psychologists [7], and longitudinally, findings were not consistent with this study. Instead of using summary mean scores for data analysis, the researcher studied each of the nine characteristics individually. Participants gave the lowest ratings for professional competence to their own profession as seen by others (perceived autostereotype). There was no significant difference in perceived autostereotypes, however, on any of the nine characteristics after a two-year IPE program.

The outcome that the nursing participant group was the only student group that demonstrated a significant difference in stereotypes is interpreted to indicate the value of the IPE initiative. Nursing students evidently carry with them certain attitudes and perceptions of themselves, other professional groups, and their own professional group as seen by others, and an interprofessional simulation-based approach served to improve those perceptions. It also indicates that nursing participants felt more confident about their own abilities, as identified through higher autostereotype and perceived autostereotype scores, after the IPE simulation. Overall, the nursing group finding is significant in that simulation-based IPE may help to improve perceptions held by nursing students of themselves and other professional groups.

Similar to the study by Barnes et al., the fact that RT and SLP heterostereotypes did not change may have two possible explanations: 1) interprofessional stereotypes are sustained and reinforced in daily contact with other HP students and faculty in class and clinic, and perhaps represent an accurate reality, or 2) the scenario and time allotted did not create an environment that allowed learners to accurately become acquainted with one another, thereby prohibiting the alteration of any preconceived perceptions [7]. Both possibilities are addressed in the limitations and recommendations portions of the article. 
Nursing Student Professional Stereotypes

Rudd, Estis, Pruitt, \& Wright

Journal of Research in Interprofessional Practice and Education

Vol. 6.1

June 2016

\section{Student impressions}

Overall, student impressions were positive with an average mean above 4 on a 1 to 5 Likert scale. The statement that rated highest was question four, "I feel more comfortable communicating with healthcare team members (nursing, RTs, and SLPs)." This result supports the ability of IPE to socialize students, thereby improving communication among future caregivers. The statement that rated lowest was question five, "The debriefing and group discussions were valuable." Future studies may serve to be better informed by asking participants more specifically, "How can debriefing sessions be more valuable?" From the perspective of faculty in debriefing sessions, students were engaged and actively participated in group discussions. One possible explanation is that there may have been confusion related to the term debrief in question five. In the open-ended question, "What would you like to see changed about this activity?" some students referred to the time before the simulation as the "brief," and commented that they would have liked to have had more preparation before the simulation, or more time to meet with their team before entering the patient's room.

\section{The SSRO}

The SSRQ is a tool that was developed in the United Kingdom by Dr. Sarah Hean, which she adapted from work by Barnes et al. [6,7,24]. Studies cited in the literature using the tool were all from outside the United States, three in the United Kingdom and one in the Netherlands $[6,23,25]$. It is important to consider the context of the SSRQ inside the culture of IPE in these countries. The European Interprofessional Practice and Education Network (EIPEN) was one of the first IPE networks to be formed on the international circuit [31]. Many studies in the literature related to IPE in HP education generate from Europe and Canada. Students in countries that have used the SSRQ may be accustomed to engaging in open dialogue about the dissimilarities of professional groups and the subsequent attitudes and perceptions that can be formed. Students in the United States, however, may be more reserved in their responses because the culture is not yet modelled around interprofessionalism and transparency.

Other factors to consider related to the SSRQ are its sensitivity and ability to reflect authentic opinions of the participants. It was obvious in data transcription that many students chose a tranquil approach, giving the same score on all characteristics to all professional groups. The study may benefit from a participant orientation to the tool itself, or tool modification in the form of measurable criteria, or competency milestones for each score of one through five. Sensitivity of the instrument may have been diluted if participants gave high scores in the pre-IPE simulation, experienced a positive interaction with participants, and then wanted to give higher scores in the post-simulation phase, but could not. This factor could have affected the ability for the RT and SLP heterostereotype measures to show statistical significance. Again, instrument modification may be valuable here, as it would give measureable objectives for each scale rating to participants.

\section{Implications}

The findings of this research have several implications for nurse educators and 
17

Nursing Student Professional Stereotypes

Rudd, Estis, Pruitt, \& Wright

Journal of Research in Interprofessional Practice and Education

Vol. 6.1

June 2016 health profession educators overall. First, the use of simulation-based IPE in HP education creates a platform for the early socialization of students and has the potential to enhance attitudes and perceptions, or stereotypes, among nursing students. Educators can use realistic models such as this one, bringing specific student groups together in the simulation lab, in order to help students get to know one another better and learn about professional roles. Not only will this serve to enrich the learning experience, it will heighten awareness of the dissimilarities among the disciplines and help students to identify value in diversity.

Specific to nursing education, this study demonstrated that nursing heterostereotypes of RT and SLP students, and nursing autostereotypes and perceived autostereotypes can be impacted by an IPE simulation approach. This has implications for nursing student professional role development. In addition, if autostereotypes and heterostereotypes are enhanced after an IPE simulation, then perhaps nursing student confidence and self-efficacy is improved. Nurse educators may find IPE initiatives like this one and others beneficial for role development, which is the first step in preparing to be an interprofessional team member.

Results of the study are reflective of students acquiring the knowledge, values, and beliefs of their own profession and other health professions that will enable them to move toward interprofessional healthcare delivery. Despite RT and SLP hetereostereotype scores remaining unchanged, student participation in the simulation and debriefing provided an invaluable experience, as it began the attitude of teamwork needed to provide collaborative care. Student reflection on their own attitudes and beliefs offers a context of preparation, and preparation is the first step to building teamwork competencies [12].

Finally, the study has implications for clinical practice. Because the collaboration of nurses, RTs, and SLPs is important for the care of patients with tracheostomies and speaking valves, this study generates an interprofessional model for other programs that will ultimately affect patient care in a positive way. Collaborative care has been shown to have positive effects in terms of patient care outcomes [1]. This IPE simulation experience, and others like it, can lead to healthcare practitioners working together more effectively for patient well-being.

\section{Limitations}

There are limitations to the study that are important to disclose and consider for future research. The smaller sample size of RT and SLP participants, compared to the nursing participant group, may affect generalizability of results. Nursing class sizes are substantially larger than RT and SLP program sizes, and due to constraints on time and resources, this could not be altered for the purposes of this study. In addition, subjects were recruited from a single university in the southeastern United States. There were significant differences in gender participation that could have affected the results of the study. The RT group consisted primarily of male participants (13 out of 21), while the SLP was entirely female, and the nursing group primarily female (84\%). The RT and nursing groups were made up of undergraduate students, while the SLP group was graduate-level students. There is a natural differ- 


\section{JRIPE}

18

Nursing Student

Professional

Stereotypes

Rudd, Estis, Pruitt, \& Wright
Journal of Research in Interprofessional Practice and Education

Vol. 6.1

June 2016
Journal of Research in Interprofessional Practice and Education

ence in academic and personal maturity in the graduate student, which may have affected difference in stereotypes scoring.

\section{Recommendations}

After considering the results, limitations, and recommendations of this study, the researchers make the following recommendations:

1. Replicate the study with a larger sample size of RT and SLP students.

2. Replicate the study with an extended longitudinal design after a variety of interprofessional simulation-based education scenarios with the same student groups.

3. Replicate the study with students representing additional occupations (e.g., physician assistant, medicine, social work).

4. Share the methodology and results with other institutions with nursing, RT, and SLP programs and replicate the study there.

5. Expand the qualitative nature of the study by asking students specific questions about other student groups after the IPE simulation, such as, "How did your perceptions of nurses change?" Also consider focus group narratives in order to further examine unchanged heterostereotype scores.

6. Replicate the study, analyzing summary mean scores for each of the nine characteristics, and examining intergroup differentiation.

7. Decrease the opportunity for halo effect by expanding the SSRQ to a more competency-based tool. List definitive criteria for each Likert scale number on each characteristic.

8. Replicate the study and use a self-efficacy tool in order to examine if nursing student confidence improved from pre- to post-IPE simulation.

9. Consider the halo effect, the inability to disregard the affective impact of global evaluation on assigning specific attributes to a person or group, in a future study and its impact on heterostereotype scores [36].

\section{Conclusion}

If learning together enhances future working together, then IPE will continue to become increasingly valued in HP education [10]. More importantly, through its ability to improve teamwork, IPE is creating a safer environment for patient care [18]. IPE also serves to help learners, specifically nursing students, develop more accurate impressions of caregivers, as the results of this study showed. Further, results of this study can inform and guide future IPE initiatives, in hopes of developing healthcare professionals that will provide high-quality, collaborative patient care to improve patient outcomes. 
19

Nursing Student Professional Stereotypes

Rudd, Estis, Pruitt, \& Wright

Journal of Research in Interprofessional Practice and Education

Vol. 6.1

June 2016

\section{References}

1. Interprofessional Education Collaborative (IPEC) Expert Panel. (2011). Core competencies for interprofessional collaborative practice: Report of an expert panel. URL: http://www.aacn.nche.edu /education-resources/ipecreport.pdf [August 2, 2014].

2. Kyrkjebo, J., Brattebo, G., \& Smith-Strom, H. (2006). Improving patient safety by using interprofessional simulation training in health professions education. Journal of Interprofessional Care, 20(5), 507-516.

3. Margalit, R., Thompson, S., Visovsky, C., Geske, J., Collier, D., Birk, T., \& Paulman, P. (2009). From professional silos to interprofessional education: Campuswide focus on quality of care. Quality Management in Health Care, 18(3), 165-173.

4. Edmonson, A., \& Roloff, K. (2009). Overcoming barriers to collaboration: Psychological safety and learning in diverse teams. In Salas, E., Goodwin, G., \& Burke, C. (Eds.), Team effectiveness in complex organizations (pp. 183-208). New York, NY: Psychology Press.

5. Hean, S. (in press). The measurement of stereotypes in the evaluation of interprofessional education. In J. Jackson \& P. Blateau (Eds.), Innovation, implementation, and evaluation: The keys to unlocking interprofessional learning. Basingstoke, UK: Palgrave. URL: http://eprints.bournemouth .ac.uk/20541/ [February 1, 2014].

6. Hean, S., Maclead Clark, J., Adams, K., \& Humphris, D. (2006). Will opposites attract? Similarities and differences in students' perceptions of the stereotype profiles of other health and social care professional groups. Journal of Interprofessional Care, 20(2), 162-181.

7. Barnes, D., Carpenter, J., \& Dickinson, C. (2000). Interprofessional education for community mental health: Attitudes to community care and professional stereotypes. Social Work Education, 19, $565-583$.

8. Carpenter, J. (1995). Doctors and nurses: Stereotypes and stereotype change in interprofessional education. Journal of Interprofessional Care, 9, 151-161.

9. Dillon, P.M., Noble, K.A., \& Kaplan, L. (2009). Simulation as a means to foster collaborative interdisciplinary education. Nursing Education Perspectives, 30(2), 87-90.

10. Thistlethwaite, J. (2012). Interprofessional education: A review of the context, learning, and the research agenda. Medical Education, 46(1), 58-70.

11. Baker, C., Pulling, C., McGraw, R., Dagnone, J.D., Hopkins-Rossseel, D., \& Medves, J. (2008). Simulation in interprofessional education for patient-centered collaborative care. Journal of Advanced Nursing, 64(4), 372-379.

12. Medical University of South Carolina. (2007, February). Creating collaborative care (C3): A quality enhancement plan (QEP). Charleston, SC: Medical University of South Carolina.

13. Blue, A.V., Mitcham, M, Smith, T., Raymond, J., \& Greenberg, R. (2010). Changing the future of health professions: Embedding interprofessional education within an academic health center. Academic Medicine, 85, 1-6.

14. Institute of Medicine. (2003). Health professions education: A bridge to quality. Committee on the Health Professions Education Summit (No. 0-309-08723-6). Washington, DC: National Academy Press.

15. Hertweck, M., Hawkins, S., Bednarek, M., Goreczny, A., Schreiber, J., \& Sterrett, S. (2012). Attitudes toward interprofessional education: Comparing physician assistant and other healthcare professions students. The Journal of Physician Assistant Education, 23(2), 8-15.

16. Lidskog, M., Lofmark, A., \& Ahlstrom, G. (2008). Learning about each other: Students' conceptions before and after interprofessional education on a training ward. Journal of Interprofessional Care, 22(5), 521-533.

17. Rodger, S., \& Hoffman, S. (2010). Where in the world is interprofessional education? A global environmental scan. Journal of Interprofessional Care, 24, 479-491.

18. Nisbet, G., Hendry, G., Rolls, G., \& Field, M. (2008). Interprofessional learning for pre-qualification healthcare students: An outcomes-based evaluation. Journal of Interprofessional Care, 22(1), 57-68.

19. Gough, S., Hellaby, M., Jones, N., \& MacKinnon, R. (2011). A review of undergraduate interprofessional simulation-based education (IPSE). Collegian, 19, 153-170.

20. Reeves, S. (2009). An overview of continuing interprofessional education. Journal of Continuing Education in the Health Professions, 29(3), 142-146.

21. Curran, V., Casimiro, L., Banfield, V., Hall, P., Lackie, K., Simmons, B., Tremblay, M., Wagner, S., \& Oandasan, I. (2009). Research for interprofessional competency-based evaluation (RICE). Journal of Interprofessional Care, 23(3), 297-300.

22. Ateah, C.A., Snow, W., Wener, P., MacDonald, L., Metge, C., Davis, P., Fricke, M., Ludwig, S., \& Anderson, J. (2010). Stereotyping as a barrier to collaboration: Does interprofessional education make a difference? Nurse Education Today, 31, 208-213. 
20

Nursing Student Professional Stereotypes

Rudd, Estis, Pruitt, \& Wright
23. Robben, S., Perry, M., Van Nieuwenhuijzen, L., Van Achterberg, T., Rikkert, M., Schers, H., Heinen, M., \& Melis, R. (2012). Impact of interprofessional education on collaboration attitudes, skills, and behavior among primary care professionals. Journal of Continuing Education in the Health Professions, 32(3), 196-204.

24. Hean, S., Macleod Clark, J., Adams, K., Humphris, D., \& Lathlean, J. (2006). Being seen by others as we see ourselves: The congruence between the ingroup and outgroup perceptions of health and social care students. Learning in Health and Social Care, 5(1), 10-22.

25. Bell, L., \& Allain, L. (2011). Exploring professional stereotypes and learning for interprofessional practice: An example from UK qualifying level social work education. Social Work Education, 30(3), 266-280.

26. Suter, E., Arndt, J., Arthur, N, Parboosingh, J, Taylor, E., \& Deutschlander, S. (2009). Role understanding and effective communication as core competencies for collaborative practice. Journal of Interprofessional Care, 23, 41-51.

27. Thannhauser, J., Russell-Mayhew, S., \& Scott, C. (2010). Measures of interprofessional education and collaboration. Journal of Interprofessional Care, 24(4), 336-349.

28. Lindqvist, S., Duncan, A., Shepstone, L., Watts, F., \& Pearce, S. (2005). Development of the attitudes to health professionals questionnaire (AHPQ): A measure to assess interprofessional attitudes. Journal of Interprofessional Care, 19(3), 269-279.

29. MacKay, S. (2004). The role perception questionnaire (RPQ): A tool for assessing undergraduate students' perceptions of the role of other professions. Journal of Interprofessional Care, 18(3), 289-302.

30. Passy-Muir, Inc. (Producer), \& Kobak, Julie (Speaker). (2013) Application of the Passy-Muir swallowing and speaking valves. URL: http://ep.passy-muir.com/educationportal/webdashboard.php [February 2, 2014].

31. The European Interprofessional Practice and Education Network (EIPEN). (2014). Our history. URL: http://www.eipen.eu/geschiedenis_9.html [July 22, 2014]. 